\title{
Study of Platelet Indices in Pregnancy Induced Hypertension
}

Dr. Balaji.S ${ }^{1}$, Dr. Kalla Ravi Teja ${ }^{2 *}$, Dr. T Govindraj ${ }^{3}$, Dr. Arun Kumar SP $^{4}$, Dr. Sneha Ravindran ${ }^{5}$

\author{
${ }^{1}$ Post graduate, Department of Pathology, SVMCH, Puducherry, India \\ ${ }^{2}$ Assistant Professor, Department of Pathology, SVMCH, Puducherry, India \\ ${ }^{3}$ Associate Professor, Department of Pathology, SVMCH, Puducherry, India \\ ${ }^{4}$ Professor and HOD, Department of Pathology, SVMCH, Puducherry, India \\ ${ }^{5}$ Post graduate, Department of Pathology, SVMCH, Puducherry, India
}

DOI: $10.36347 /$ sjams.2020.v08i08.006

| Received: 02.08.2020 | Accepted: 09.08.2020 | Published: 13.08.2020

*Corresponding author: Kalla Ravi Teja

Abstract

Original Research Article

Introduction: Pregnancy-induced hypertension (PIH) is the most common disorder of pregnancy affecting approximately $5-7 \%$ of pregnancies and is a significant cause of maternal and fetal morbidity and mortality. Platelet count and platelet indices are simple and cost effective method of prediction of pregnancy induced hypertension. This study is aimed to compare platelet indices between normal pregnancy and cases with pregnancy induced hypertension and study the association of platelet indices and pregnancy induced hypertension. Materials and methods: Prospective case control study, conducted in the department of pathology with cases having BP> 140/90, detected after 20 weeks of pregnancy and control group with uneventful pregnancies. Under aseptic precautions samples are collected in EDTA containers and analyzed for platelet indices using automated analyzer. Result: Maximum gestational age of incidence of pregnancy induced hypertension is between 26 and 41 weeks with mean gestational age of 35 weeks. Platelet count showed gradual decrease in pregnancy induced hypertension cases when compared to normal pregnancy. Mean platelet volume showed gradual increase when compared to normal pregnancy. Conclusion: Study shows platelet count and platelet indices are simple and cost effective modality for early recognition of pregnancy induced hypertension so that it will help in prevention of complications.

Keywords: Pregnancy induced hypertension, pre- eclampsia, platelet indices, platelet count.

Copyright @ 2020: This is an open-access article distributed under the terms of the Creative Commons Attribution license which permits unrestricted use, distribution, and reproduction in any medium for non-commercial use (NonCommercial, or CC-BY-NC) provided the original author and source are credited.

\section{INTRODUCTION}

Pregnancy-induced hypertension (PIH) is the most common disorder of pregnancy affecting approximately $5-7 \%$ of pregnancies and is a significant cause of maternal and fetal morbidity and mortality. The incidence of PIH in India ranges from 5\% to $15 \%$ [1].

Majority of patients remains in mild to moderate group and does not have any obstetric problem, certain proportion of patients; the risk to the mother can be significant and includes the possible development of disseminated intravascular coagulation (DIC), intracranial hemorrhage, renal failure, retinal detachment, pulmonary edema, liver rupture, abruptio placentae, and death [1].

$\mathrm{PE}$ is characterized by hypertension (blood pressure $>140 / 90 \mathrm{~mm} \mathrm{Hg}$ ), proteinuria $(>0.3 \mathrm{~g} / \mathrm{d}$ ), edema and other symptoms and may begin as early as the 20th gestational week and last for 6 weeks after delivery [2]. PIH is associated with $16 \%$ of all maternal mortality and $20 \%$ of all perinatal mortality in India [3].

Pregnancy induced hypertension (PIH) is defined as hypertension that develops as the direct result of the gravid state. It includes, i) Gestational hypertension, ii) Preeclampsia, iii) Eclampsia [3].

Various major hematological changes like quantitative and qualitative platelet abnormalities, alteration in hemoglobin concentration and altered blood indices parameters and hypercoagulable state may be seen [4].

Preeclampsia is a highly thrombotic and procoagulant state with platelet activation and thrombin and fibrin formation. About $20 \%$ of PIH patients have altered coagulation study profile [4].

Recent studies suggest that platelet parameters like platelet indices are most simple and cost effective methods for prediction of PIH, way before the 
appearance of derangements in PT, APTT, TT values [5].

So we undertook this study to see that if there is any variation in platelet count and indices like MPV \& PDW in pregnancy induced hypertension.

\section{Materials \& Methods}

AIM

To study association of platelet indices between normal pregnancy and pregnancy induced hypertension.

\section{OBJECTIVES}

1) To study the platelet indices in pregnancy induced hypertensive patients.

2) To study the platelet indices in normal pregnant women of more than 20 weeks.

3) To compare the platelet indices between the normal and hypertensive pregnant patients.

\section{Study area}

The study was conducted in Sri Venkateshwaraa Medical College Hospital \& Research Institute, Ariyur, and Puducherry.

\section{Study design}

Cross sectional study

\section{Sample Size}

50 pregnant women with $\mathrm{PIH}$

50 pregnant women with no complications

\section{Inclusion Criteria}

CASES: Women having (B.P.>140/90 mmHg) and significant proteinuria (>300 mg per $24 \mathrm{hrs}$ ) and/or edema were treated as preeclampsia.

CONTROLS: Normotensive pregnancies more than 20 weeks.

\section{Exclusion Criteria}

- Cardiovascular disease.

- Renal and Hepatic disorders.

- Eclampsia.

- Chronic hypertension.

\section{Methodolohy}

The present study is a cross sectional study carried out in pregnant women in the department pathology at Sri Venkateshwaraa Medical College Hospital \& Research Institute, after obtaining consent from the patient. Clinical details like blood pressure, $\mathrm{G}$ P L A, weeks of gestation, any history of past illness will be obtained.
Then $5 \mathrm{ml}$ of venous blood will be drawn from the study population by venipuncture using a disposable syringe under aseptic precautions and are taken in tubes containing EDTA. Then the sample is processed for platelet indices in automatized counter Mindray IP 5051 five part automated analyzer.

\section{RESULTS}

The mean gestational age of incidence of pregnancy hypertension is 35 with a range between 26 and 41 weeks. The mean platelet count in PIH cases in both primi and multigravida are1 reduced when compared with platelet count in normal pregnancy. The mean platelet volume is increased in PIH when compared to that of normal pregnancy. Though platelet distribution width showed increase in pregnancy induced hypertension it was not significant with $\mathrm{p}$ value of more than 1 .

\section{DisCUSSION}

Present prospective observational analytical case control study included 100 subjects, out of which 50 were controls and 50 were having PIH. In this study an attempt was made to assess the role of platelet indices in assessment of preeclampsia.

In present study we found an increase in MPV \& PDW values from normotensive pregnant women to pre-eclampsia which correlated well with other studies.

In our study mean Platelet count is 1.8 lakhs in preeclampsia which is comparable with Mohapatra et al. who observed platelet count as 1.8 lakhs \& Vrunda et al. who observed the value of Platelet count as 1.4 in preeclampsia [5-8]

In our study MPV in preeclampsia which is comparable with Giles et al. who observed MPV of 9.9, Annam et al. observed the value of MPV as 10.3 in preeclampsia [5-8].

In our study PDW is 12 in preeclampsia which is comparable with Giles et al. who observed PDW of 16 \& Annam et al. who observed the value of PDW as 15.51 in preeclampsia $[5,6,7,8]$.

Pre- eclampsia affects approximately $6 \%$ of all pregnancies. Women with severe pre-eclampsia may develop variety of hematological aberrations. Thrombocytopenia complicating pregnancy is reported relatively frequently in severe pre- eclampsia with occurrence ranging at 11 to $29 \%$. The incidence of thrombocytopenia associated with pregnancy induced hypertension in our study was $42.11 \%$, which is much higher than earlier reported cases $[9,10]$. 
Balaji.S et al., Sch J App Med Sci, August, 2020; 8(8): 1828-1832

COMPARISON WITH OTHER STUDIES

\begin{tabular}{|c|c|l|l|l|l|}
\hline GROUP & PARAMETER & $\begin{array}{c}\text { Mohapatra } \\
\text { et al. }[\mathbf{6}]\end{array}$ & $\begin{array}{c}\text { Vrunda } \text { et } \\
\text { al. } \text { [7] }\end{array}$ & $\begin{array}{c}\text { Rabia } \text { et } \\
\text { al. } \text { [5] }\end{array}$ & $\begin{array}{c}\text { Present } \\
\text { study }\end{array}$ \\
\hline NORMAL PREGNANCY & Platelet count(lakhs) & 2.3 & 2.2 & 2.4 & 2.2 \\
\hline PIH & Platelet count(lakhs) & 1.8 & 1.4 & 1.9 & 1.8 \\
\hline
\end{tabular}

\begin{tabular}{|c|l|l|l|l|l|}
\hline GROUP & PARAMETERS & \multicolumn{1}{|c|}{$\begin{array}{c}\text { Annam } \text { et. } \text { al. } \\
{[\mathbf{5}]}\end{array}$} & $\begin{array}{c}\text { Giles } \text { et al. } \\
{[\mathbf{8}]}\end{array}$ & $\begin{array}{c}\text { Rabia } \text { et. } \\
\text { al. } \text { [5] }\end{array}$ & $\begin{array}{c}\text { Present } \\
\text { study }\end{array}$ \\
\hline \multirow{2}{*}{ NORMAL PREGNANCY } & MPV & 8.6 & 8.7 & 8.4 & 9 \\
\cline { 2 - 6 } & PDW & 11.07 & 12 & 12 & 11 \\
\hline \multirow{2}{*}{ PIH } & MPV & 10.3 & 9.9 & 9 & 10 \\
\cline { 2 - 6 } & PDW & 15.5 & 16 & 16.29 & 12 \\
\hline
\end{tabular}

\section{Statistical Analysis}

GESTATIONAL AGE

\begin{tabular}{|l|l|l|l|l|l|}
\hline GROUP & N & MINIMUM & MAXIUM & MEAN & SD \\
\hline Normal pregnancy & 50 & 22 & 41 & 32.80 & 4.853 \\
\hline $\begin{array}{l}\text { Pregnancy induced } \\
\text { hypertension }\end{array}$ & 50 & 26 & 41 & 35.16 & 3.727 \\
\hline
\end{tabular}

\begin{tabular}{|c|l|r|r|r|r|r|}
\hline \multicolumn{7}{|c|}{ DESCRIPTIVE STATISTICS- CASES } \\
\hline \multicolumn{1}{|c|}{ PARITY } & N & MINIMUM & \multicolumn{1}{c|}{ MAXIMUM } & \multicolumn{1}{c|}{ MEAN } & \multicolumn{1}{c|}{ SD } \\
\hline \multirow{3}{*}{ Primi } & Platelet Count (lakhs) & 35 & 72000 & 410000 & 194571.43 & 84136 \\
\cline { 2 - 7 } & PDW (fl) & 35 & 8.00 & 18.20 & 12.2571 & 2.4 \\
\cline { 2 - 7 } & MPV (fl) & 35 & 7.80 & 38.30 & 10.4971 & 4.9 \\
\hline \multirow{3}{*}{ Multi } & Platelet Count (lakhs) & 15 & 100000 & 260000 & 167333.33 & 47729 \\
\cline { 2 - 7 } & PDW ( fl) & 15 & 8.00 & 16.60 & 11.4800 & 2.4 \\
\cline { 2 - 7 } & MPV ( fl) & 15 & 7.60 & 10.90 & 9.3533 & 0.9 \\
\hline
\end{tabular}

\begin{tabular}{|c|l|c|r|r|r|r|}
\hline \multicolumn{7}{|c|}{ DESCRIPTIVE STATISTICS-CONTROL } \\
\hline \multicolumn{1}{|c|}{ PARITY } & N & MINIMUM & \multicolumn{1}{c|}{ MAXIMUM } & \multicolumn{1}{c|}{ MEAN } & \multicolumn{1}{c|}{ SD } \\
\hline \multirow{3}{*}{ Primi } & Platelet Count (lakh) & 29 & 150000 & 400000 & 221586.21 & 57101.737 \\
\cline { 2 - 7 } & PDW ( fl) & 29 & 8.10 & 15.10 & 10.9414 & 1.77432 \\
\cline { 2 - 7 } & MPV (fl) & 29 & 8.00 & 10.40 & 9.2517 & .67062 \\
\hline \multirow{3}{*}{ Multi } & Platelet Count (lakh) & 21 & 150000 & 400000 & 218761.90 & 56044.540 \\
\cline { 2 - 7 } & PDW (fl) & 21 & 8.40 & 14.20 & 11.3429 & 2.01880 \\
\cline { 2 - 7 } & MPV (fl) & 21 & 8.00 & 12.10 & 9.3095 & .94123 \\
\hline
\end{tabular}

CHI SQUARE TEST -PLATELETS: P VALUE-0.005 (SIGNIFICANT)

\begin{tabular}{|c|l|l|l|}
\hline GROUP & < 2 LAKHS/CUMM & $>\mathbf{2}$ LAKHS/CUMM & TOTAL \\
\hline NORMAL PREGNANCY & 22 & 28 & 50 \\
\hline PIH & 36 & 14 & 50 \\
\hline TOTAL & 58 & 42 & 100 \\
\hline
\end{tabular}

CHI SQUARE TEST -PDW: P VALUE-0.151 (NOT SIGNIFICANT)

\begin{tabular}{|c|l|l|l|}
\hline GROUP & $<\mathbf{1 2 f l}$ & $>\mathbf{1 2 f l}$ & TOTAL \\
\hline NORMAL PREGNANCY & 34 & 16 & 50 \\
\hline PIH & 27 & 23 & 50 \\
\hline TOTAL & 61 & 39 & 100 \\
\hline
\end{tabular}

CHI SQUARE TEST - MPV: P VALUE-0.009 (SIGNIFICANT)
\begin{tabular}{|l|l|l|l|}
\hline GROUP & $<\mathbf{1 0 f l}$ & $>\mathbf{1 0 f l}$ & TOTAL \\
\hline NORMAL PREGNANCY & 44 & 6 & 50 \\
\hline PIH & 33 & 17 & 50 \\
\hline TOTAL & 77 & 23 & 100 \\
\hline
\end{tabular}



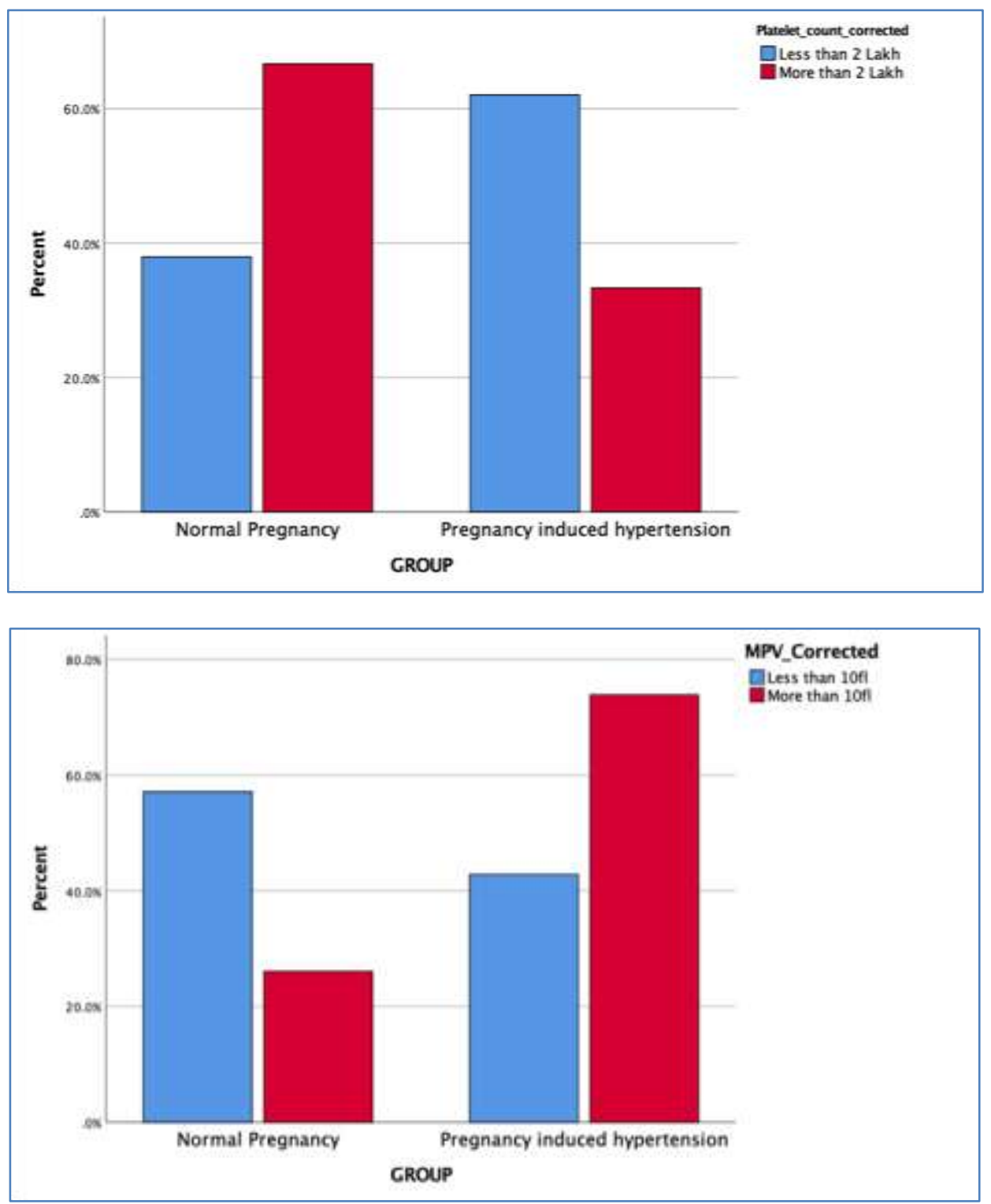

\section{ConClusion}

Since pregnancy induced hypertension is the most common disorder complicating pregnancy so it is mandatory to detect and treat earlier to prevent complications.

Since platelet count and platelet indices (PDW, MPV) estimation are simple and cost effective and so it can be used for the assessment of severity of preeclampsia and disease progression to eclampsia.

Since platelet count and indices are routinely done it is selected as an initial parameter for screening and assessment of pregnancy induced hypertension and initiation of earlier treatment.

Drawback of the study is thought it is a screening test its not confirmatory, so further investigations of coagulation parameters like prothrombin time, activated partial thromboplastin time, fibrin degradation products, $\mathrm{d}$ dimer are required for confirmation.

Hence further studies with larger population and further investigation parameters are required to generalize the findings in the population.

Due to low socioeconomic status, attitude, poor health education and lack of regular antenatal check-up the incidence of PIH is more in developing countries like India

\section{REFERENCES}

1. Jyothi Shetty, Sudha Rao, MH Kulkarni. Hematological changes in pregnancy induced hypertension. IJSS March. 2016, 462.

2. Han L, Liu X, Li H, Zou J, Yang Z, Han J, Huang W, Yu L, Zheng Y, Li L. Blood coagulation parameters and platelet indices: changes in normal and preeclamptic pregnancies and predictive values 
for preeclampsia. PloS one. 2014 Dec 2;9(12):e114488.

3. Nirmala T, Kumar Pradeep L, Vani BR, Murthy Srinivasa V, Geetha RL. Study of coagulation profile in pregnancy induced hypertension. Indian journal of pathology and oncology. January-March. 2015, P1-6.

4. Chhabra AC, Patel NR. A retrospective study of coagulation parameters in patients of pregnancy induced hypertension. Indian Journal of Pathology and Oncology. 2018 Jul;5(3):411-4.

5. Siddiqui RP, Chandrakar K, Varma R, Shrivastava S. Study on platelet indices in pregnancy induced hypertension. J Evidence Based Med Healthcare. 2015 Nov 2; 2:8035-40.

6. Mohapatra S, Pradhan BB, Satpathy UK, Mohanty A, Pattnaik JR. Plateeltestimation: Prognostic values in pregnancy induced hypertension. Indian J physiol pharmacol. 2007; 51: 160-64.

7. Vrunda JK, Saila S. Lowered platelet count.A prognostic index in pregnancy induced hypertension. J Obstet Gynaecol Ind. 2004; 54: 235-6.

8. Giles C. The platelet count and mean platelet volume.Br J Haematol.1981 May; 48 (1): 31-7.

9. Romero R. Clinical significance, prevalence and natural history of thrombocytopenia in pregnancy induced hypertension. Am J perinatal. 1989; 6:328.

10. Prichart JA. Coagulation changes in eclampsia: their frequency and pathogenesis. Am J Obstet Gynecol. 1976;4:855-64. 